\title{
Reproductive Biology and Effect of Arachidonic Acid Level in Broodstock Diet on Final Maturation of the Hawaiian Limpet Cellana sandwicensis
}

\section{Nhan Thai Hua ${ }^{1,2 *}$ and Harry $\mathrm{Ako}^{2}$}

${ }^{1}$ Department of Coastal Aquaculture, College of Aquaculture and Fisheries, Cantho University, Vietnam

${ }^{2}$ Department of Molecular Biosciences and Bioengineering, University of Hawaii at Manoa, 1955 East West Road, Room 218, Honolulu 96822, USA

\begin{abstract}
This study examined the natural spawning season of the Hawaiian limpet or opihi Cellana sandwicensis, by monthly measurement of Gonado Somatic Index (GSI) and histology analysis of the gonad of the animals over the course of a year. The highest GSI values were found in November 2011, January 2012 and from November to December 2012. These GSI values were significantly higher than GSI of opihi collected from other months, suggesting a spawning season for C. sandwicensis from November to January. Significantly lower GSI values were observed from February to September 2012 indicate that opihi were in a resting phase, followed by a final maturation phase which began in October. This study provided an important exogenous key factor for developing an affective induction of opihi gonad maturation in the laboratory. The final maturation of opihi was investigated by supplementation of arachidonic acid (ARA) in the broodstock diet, fed to the animals during the natural final maturation and spawning season. Adult opihi $(3.07 \pm 0.22 \mathrm{~cm}$ in shell length) were fed with two different dietary levels of ARA, $0.24 \%$ and $0.39 \%$ at the same ARA/EPA (eicosapentaenoic acid) ratio of 0.7 for 95 days. The GSI values of opihi reached to final maturation stage of $24.5 \%$ and $23.7 \%$ for $0.24 \%$ ARA and $0.39 \%$ ARA diets respectively, and were significantly higher than GSI of opihi (6.11\%) that were fed with the control diet without supplementation of ARA after 75 days. The average eggs diameters were $123 \pm 4.23 \mu \mathrm{m}$ for $0.24 \%$ ARA and $121 \pm 5.93 \mu \mathrm{m}$ for $0.39 \%$ ARA diets. Histology analysis also confirmed that the eggs were ripe. However, these mature opihi did not undergo to natural spawning and GSI values were winding down after 95 days, suggesting that a natural reabsorption had occurred. The results of this study indicate that supplementation of ARA to EPA ratio of 0.7 during the correct photoperiod were found to have potential for inducing final maturation in limpets.
\end{abstract}

Keywords: Hawaiian limpets; Opihi Cellana sandwicensis; Spawning season; Final maturation; Arachidonic acid

\section{Introduction}

The Hawaiian limpets Cellana are locally known as opihi. The high market value of the opihi leads to the two unfortunate issues. The intensive harvesting for private consumption and commercially have led to overharvesting and extinction in many areas of Hawaiian Islands $[1,2]$. Many people have died while collecting opihi due to the extreme danger of the animal's habitat, steep cliffs washed by high waves and rough water. These problems have indicated the benefits of aquaculture of opihi in Hawaii, and efforts to develop aquaculture technology for opihi have recently started [3]. We have developed a holding system that allows handling opihi with minimum mortality in an aquaculture system. We also developed an optimal formulated feed available for aquaculture of opihi. We needed to be able to reproduce opihi in laboratory conditions.

Determination of the natural reproductive cycles of a new species and the relative possible exogenous factors that control the reproduction processes are very important [4]. These would relate to developing effective techniques for induction of final maturation and spawning in the laboratory. Although there have been several studies of the reproductive biology of limpets, Cellana [5], Patelloida murfria [6], Patella vulgate and P. ulyssiponensis [7], there is a lack of information on the reproduction of the Hawaiian limpet Cellana sandwicensis. The present study was conducted to examine the spawning season, sex ratio, and potential fecundity of $C$. sandwicensis. Our further goal was to provide insight information into the induction of final maturation and spawning of this species.

Dietary manipulation of nutrition of broodstock was found to effect on the final maturation and fecundity of aquatic animals [8]. Arachidonic acid (ARA) serves as a precursor for prostaglandins which have a key function in the reproductive process $[9,10]$. Final maturation of aquatic animals might involve the relative ARA to EPA (eicosapentaenoic acid) ratio because of prostaglandin potency production. Several studies have shown that an appropriate ARA/EPA level in diet will produce final maturation and high seed production in several fish species. For example, the ARA/EPA ratio of 0.69 was found to be associated with a significantly higher fertilization rates in mullet Mugil cephalus [11]. Similarly, the addition of ARA in broodstock diets to obtain a relative ARA/EPA ratio of 0.70 induced the final maturation and high seed production in Japanese flounder Paralichthys olivaceus [12]. For invertebrates, supplementation of ARA into broodstock diet affected egg development and spawning in shrimp Penaeus monodon [13]. Another study showed that insufficient ARA, EPA in seaweed Gracilariopsis bailine might influence the reproductive performance of abalone as compared to an artificial diet [14]. Opihi prefer to feed on benthic diatoms such as Nitzschia, Amphora, and Navicula, which were predominant in stomach contents [3]. The studies of several benthic diatoms for ARA and EPA showed that their ARA/EPA ratios vary, ranging from 0.02 to 0.97 [15-17]. An ARA/EPA ratio of about 0.70 was found in Nitzschia. Other benthic diatoms such as Chaetoceros species contain ARA/EPA ratios of 0.51 to 0.97 , which are also close to

*Corresponding author: Nhan Thai Hua, Department of Molecular Biosciences and Bioengineering, University of Hawaii at Manoa, USA, Tel: 1-808-956-4219; E-mail: huanhan@hawaii.edu

Received June 13, 2014; Accepted July 29, 2014; Published August 04, 2014

Citation: Hua NT, Ako H (2014) Reproductive Biology and Effect of Arachidonic Acid Level in Broodstock Diet on Final Maturation of the Hawaiian Limpet Cellana sandwicensis. J Aquac Res Development 5: 256. doi:10.4172/2155-9546.1000256

Copyright: (๑) 2014 Hua NT, et al. This is an open-access article distributed under the terms of the Creative Commons Attribution License, which permits unrestricted use, distribution, and reproduction in any medium, provided the original author and source are credited. 
Citation: Hua NT, Ako H (2014) Reproductive Biology and Effect of Arachidonic Acid Level in Broodstock Diet on Final Maturation of the Hawaiian Limpet Cellana sandwicensis. J Aquac Res Development 5: 256. doi:10.4172/2155-9546.1000256

Page 2 of 8

0.70, but there is a lower level in Amphora (0.27), Navicula (0.10) and Thalassiosira (0.02). It is possible that the ARA/EPA ratio about 0.70 in these benthic diatoms contribute to the final maturation of opihi. Because of the previous studies on ARA/EPA ratios, we felt that the amount of ARA in the diet would be a more productive line of research. Therefore, we chose to investigate the effect of a diet with the same ARA/EPA ratio (0.70) on the maturation of opihi.

In the present study, besides the determination of the natural spawning season, the effect of different ARA levels on the induction of final maturation of opihi was also investigated. The final maturation of opihi was assessed when they were fed with the two different dietary ARA levels with the same ARA/EPA ratio of 0.70 . Gonadosomatic index and egg development were examined for 45, 75 and 95 days.

\section{Materials and Methods}

\section{Animals collection}

Collecting opihi is restricted by law in Hawaii. The current law that regulates the harvest size for all Cellana species is 1.25 inches (approximately $3.2 \mathrm{~cm}$ ) in shell length because it is believed that the animals attain the reproductive stage at this size and only animals that have had a chance to spawn would be subjected to harvest. At least twelve adult opihi with legal sizes were collected monthly from November 2011 to December 2012. They were collected at the shoreline from remote areas on Oahu Island, Hawaii, USA.

\section{Gonad samples}

After collection, they were transferred to the laboratory and were carefully dissected to obtain their gonad weight and body weight (soft body tissue). The GSI was calculated according to the equation GSI= $(\mathrm{GW} / \mathrm{BW}) \times 100$; where $\mathrm{GW}$ is gonad weight and BW is body weight or soft body tissue. Several gonads each month were also used for histological examination to determine egg developmental stage. After dissecting, their gonads were immediately fixed in $10 \%$ formalin for histological examination. Histological sections were about 5-7 $\mu \mathrm{m}$ each and were stained with hematoxylin and eosin at the Pathology Laboratory, Queens Hospital, Honolulu, Hawaii.

The classification of maturity stages of gonad development of opihi were characterized as described according to other reports for limpets species $[7,18]$. The sex ratio of apparent male and female opihi was successfully determined during the spawning season. It is noted that the sexual determination required killing the animal, as their gonads were not apparent by visual observation during live examination.

Potential fecundity was defined as the total number of counted oocytes present in a mature ripe female opihi, and was examined for at least 3 opihi during the peak GSI from November to January in what believed to be the spawning season. The gonads were carefully extracted from the animals, then weighed to obtain the gonad weight. A sub-sample of approximately $0.10 \mathrm{~g}$ was taken at different locations in each ovary: apical part; middle; and near the base. Each subsample was then mixed with $5 \mathrm{ml}$ formalin (10\%). The numbers of oocytes were counted and total number of oocytes in the ovary was estimated and presented as potential fecundity.

\section{Induction of final maturation}

Experimental diet: The base formulated diet and protocol of dietary preparation was made according to our previous description [3]. Three experimental diets were used (Table 1). The first diet served as a control without additional ARA. The second diet, $0.24 \%$ pure ARA

\begin{tabular}{|l|c|c|c|}
\hline Ingredient $\mathbf{( g / 1 0 0 ~ g ) ~}$ & Control & $\mathbf{0 . 2 4} \%$ ARA & $\mathbf{0 . 3 9 \%}$ ARA \\
\hline Fishmeal & 16.5 & 16.5 & 16.5 \\
\hline Defatted soy meal & 11.5 & 11.5 & 11.5 \\
\hline Krill meal & 4.50 & 4.50 & 4.50 \\
\hline Porphyra ${ }^{1}$ & 14.0 & 14.0 & 14.0 \\
\hline Wheat flour & 41.3 & 41.3 & 41.3 \\
\hline Diatomacetous earth & 5.80 & 5.59 & 3.65 \\
\hline Alginate & 5.00 & 5.00 & 5.00 \\
\hline Corn oil & 0.10 & 0.10 & - \\
\hline Menhaden oil & 0.10 & 0.10 & 2.00 \\
\hline Mixed vitamin ${ }^{2}$ & 1.00 & 1.00 & 1.00 \\
\hline Cholesterol & 0.20 & 0.20 & 0.20 \\
\hline ARA ${ }^{3}$ & - & 0.24 & 0.39 \\
\hline Total & 100 & 100 & 100 \\
\hline Calculated nutrients "as fed" & & & \\
\hline Protein & 26.5 & 26.5 & 26.5 \\
\hline Lipid & 2.69 & 2.69 & 4.69 \\
\hline ARA & 0.02 & 0.24 & 0.39 \\
\hline EPA & 0.34 & 0.34 & 0.56 \\
\hline ARA/EPA & 0.03 & 0.70 & 0.70 \\
\hline
\end{tabular}

${ }^{1}$ This is commercial seasoned seaweed known as nori or the red algae Porphyra tenera or yezoensis. Nishimoto Trading Co. Ltd., Korea

${ }^{2}$ Commercial vitamin mix used for coldwater fishes, and was kindly provided from Dr. Warren Dominy (Oceanic Institute, USA).

${ }^{3}$ Purified ARA, MP Biomedicals, LLC, Fisher Science.

Table 1: Composition of formulated diets with different ARA levels.

\begin{tabular}{|l|c|c|c|}
\hline Fatty acid & Control & $\mathbf{0 . 2 4} \%$ ARA & $\mathbf{0 . 3 9 \%}$ ARA \\
\hline C14:0 & 0.26 & 0.22 & 0.23 \\
\hline C16:0 & 1.27 & 1.08 & 0.97 \\
\hline C16:1n-7 & 0.28 & 0.24 & 0.26 \\
\hline C18:0 & 0.18 & 0.16 & 0.15 \\
\hline C18:1n-9 & 1.08 & 0.93 & 0.84 \\
\hline C18:2n-6 & 2.03 & 1.71 & 1.67 \\
\hline C18:3n-3 & 0.11 & 0.10 & 0.09 \\
\hline C18:4n-3 & 0.01 & - & 0.01 \\
\hline C20:0 & 0.05 & 0.05 & 0.05 \\
\hline C20:1n-9 & 0.01 & 0.01 & 0.01 \\
\hline C20:4n-6 & 0.02 & 0.24 & 0.39 \\
\hline C20:5n-3 & 0.38 & 0.34 & 0.56 \\
\hline C22:5n-3 & 0.01 & 0.01 & 0.01 \\
\hline C22: $5 n-6$ & 0.03 & 0.03 & 0.04 \\
\hline C22:6n-3 & 0.17 & 0.15 & 0.19 \\
\hline$\sum n-3$ & 0.67 & 0.76 & 1.01 \\
\hline$\sum n-6$ & 2.08 & 1.98 & 2.11 \\
\hline ARA/EPA & 0.05 & 0.70 & 0.70 \\
\hline
\end{tabular}

Table 2: Fatty acid profiles $(\mathrm{g} / 100 \mathrm{~g})$ of the maturation diets.

(Purified ARA, MP Biomedicals, LLC, Fisher Science) was added to have a target level of ARA at a ARA/EPA ratio of 0.70 . The third diet is the same as the second diet except fish oil was raised up to $2.0 \%$ to boost up EPA level. It triggered increasing the ARA level in diet $0.39 \%$.

Protein and lipids were calculated "as fed" and are given in Table 1. Fatty acid profiles of the diets were analyzed by Dr. Ju at the Aquatic Feeds and Nutrition Laboratory, Oceanic Institute, Hawaii, USA, according to described method of Ju [19]. The results are shown in Table 2 .

Experimental animals: Adult opihi used for this experiment were collected from the wild at remote shoreline areas in Oahu Island, Hawaii, USA. After collection the animals were immediately transferred 
Citation: Hua NT, Ako H (2014) Reproductive Biology and Effect of Arachidonic Acid Level in Broodstock Diet on Final Maturation of the Hawaiian Limpet Cellana sandwicensis. J Aquac Res Development 5: 256. doi:10.4172/2155-9546.1000256

to the laboratory, University of Hawaii at Manoa, and placed in aquaria with plastic liners, containing algae seeded with benthic diatoms from Hawaii Institute of Marine Biology. An aquarium biofilter system (586 $\mathrm{L} \mathrm{h}^{-1}$ ) was used to simulate the water movement. They were held for about 3 days of acclimation. Thereafter, nine opihi $(3.07 \pm 0.22 \mathrm{~cm}$ in shell length) were selected for each dietary test. They were placed into an aquarium $(75 \mathrm{~cm} \times 30 \mathrm{~cm} \times 30 \mathrm{~cm}$; length, width, height $)$ with plastic liners. Nine animals per aquarium, three aquaria were used. The same biofilter system above was used for each aquarium.

The experiment was conducted for 95 days during the natural maturation and spawning seasons from September 2013 to January 2014. Nine squares of feed $\left(1.0 \mathrm{~cm}^{2} /\right.$ piece; approximately $130 \mathrm{mg}$ mean weight; $48.5 \%$ dry weight) were fed in the evening at 18:00 daily for nine opihi in each aquarium. Our previous study showed that they fed about $1 \%$ dry matter body weight per day. Uneaten feed was removed the next morning. Seawater was exchanged about $30 \%$ every week. Salinity was maintained at $35 \%$, monitored every three days, and temperature $\left(23-25^{\circ} \mathrm{C}\right)$ was held at ambient conditions.

\section{Maturation evaluation}

Prior to beginning the experiment, several animals were sacrificed to obtain initial GSI and gonad status. In order to assess the growth of opihi gonad, three animals were randomly sampled after 45 days, 75 days and 95 days. Their gonads were extracted and weighed to obtain gonad weight for the calculation of the GSI as described above. The gonad development stage was also determined histologically. Egg development in terms of diameter was also measured.

\section{Statistical analysis}

One-way ANOVA analysis, followed by Tukey test was used to compare the difference in mean GSI of animals among the collections and in the maturation trials.

\section{Results}

\section{Spawning season}

Figure 1 is a graphical representation of GSI values monthly from

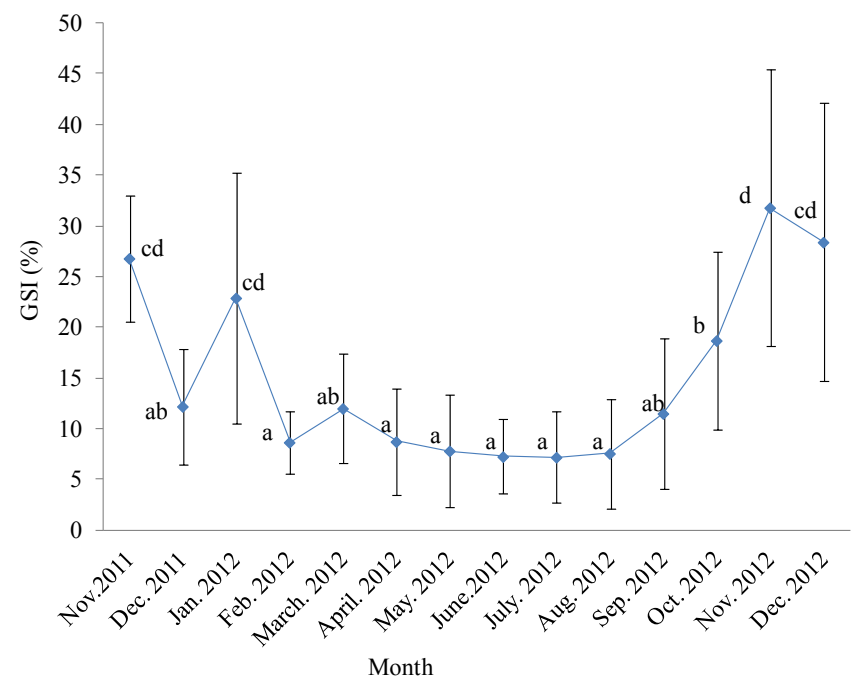

Figure 1: Seasonal changes in GSI of opihi C. sandwicensis. ${ }^{\mathrm{a}, \mathrm{b}, \mathrm{c}, \mathrm{d}}$ different letters indicate significant difference in the average GSI of animals $(n=12-30)$ sampled from November 2011 to December 2012.

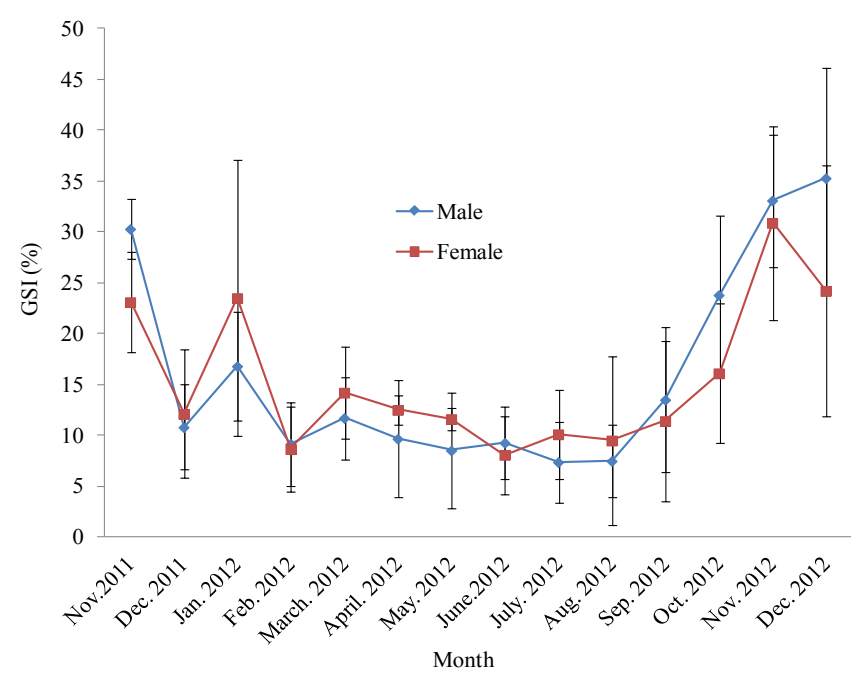

Figure 2: Seasonal changes in GSI of males $(n=7-19)$ and females $(n=8-14)$ opihi C. sandwicensis sampled from November 2011to December 2012.

\begin{tabular}{|l|c|c|}
\hline \multirow{2}{*}{ Month } & \multicolumn{2}{|c|}{ GSI (\%) } \\
\cline { 2 - 3 } & Male & Female \\
\hline Nov. 2011 & $30.3 \pm 2.99^{\text {cd }}$ & $23.1 \pm 4.95^{\mathrm{abc}}$ \\
\hline Dec. 2011 & $10.8 \pm 4.20^{\mathrm{a}}$ & $11.0 \pm 4.67^{\mathrm{a}}$ \\
\hline Jan. 2012 & $16.8 \pm 5.31^{\mathrm{ab}}$ & $26.4 \pm 11.0^{\mathrm{bc}}$ \\
\hline Feb. 2012 & $9.16 \pm 4.09^{\mathrm{a}}$ & $8.65 \pm 4.14^{\mathrm{a}}$ \\
\hline March 2012 & $11.7 \pm 4.04^{\mathrm{a}}$ & $14.4 \pm 4.60^{\mathrm{ab}}$ \\
\hline April 2012 & $9.66 \pm 5.79^{\mathrm{a}}$ & $11.5 \pm 0.87^{\mathrm{ab}}$ \\
\hline May 2012 & $8.51 \pm 5.64^{\mathrm{a}}$ & $11.6 \pm 1.06^{\mathrm{ab}}$ \\
\hline June 2012 & $9.26 \pm 3.5^{\mathrm{a}}$ & $10.1 \pm 4.28^{\mathrm{a}}$ \\
\hline July 2012 & $7.36 \pm 4.00^{\mathrm{a}}$ & $10.1 \pm 4.36^{\mathrm{a}}$ \\
\hline Aug. 2012 & $7.47 \pm 3.62^{\mathrm{a}}$ & $9.49 \pm 8.32^{\mathrm{a}}$ \\
\hline Sep. 2012 & $13.5 \pm 7.08^{\mathrm{ab}}$ & $11.4 \pm 7.88^{\mathrm{ab}}$ \\
\hline Oct. 2012 & $23.8 \pm 7.78^{\mathrm{bc}}$ & $16.1 \pm 6.86^{\mathrm{abc}}$ \\
\hline Nov. 2012 & $33.1 \pm 6.52^{\mathrm{cd}}$ & $30.9 \pm 9.52^{\mathrm{c}}$ \\
\hline Dec. 2012 & $35.3 \pm 10.8^{\mathrm{d}}$ & $24.2 \pm 12.3^{\mathrm{abc}}$ \\
\hline
\end{tabular}

$a, b, c, d$ the same letters indicate no significant difference in the average percentage GSI of male and female in the same column.

Table 3: GSI of male and female opihi C. sandwicensis throughout the study.

November 2011 to December 2012. The average GSI ranged from 7.19 $\pm 4.51 \%$ to $31.8 \pm 7.72 \%$ and one-way ANOVA analysis, followed by Tukey test revealed that there was a significant difference $(P<0.001)$ in GSI of animals during the study period. The highest average GSI of C. sandwicensis was noticed between November and January. This suggests the relative spawning seasons of opihi would occur from November to January. The GSI in December 2011 was reduced significantly lower than in November 2011, suggesting either the spawning had just occurred or the GSI value in this month was outliner as compared to the GSI of opihi in December 2012. GSI dropped in February, suggesting the end of the spawning period. The lowest GSI was observed from March to August, but GSI gradually increased from September to November.

The pattern of gonad development of males and females $C$. sandwicensis is shown in the Figure 2. Overall, a similar trend was found in GSI of both sexes throughout the study. Statistical analysis showed that there was no significant $(P>0.05)$ difference between GSI of males and females caught in the same month. The data seem to be 
Citation: Hua NT, Ako H (2014) Reproductive Biology and Effect of Arachidonic Acid Level in Broodstock Diet on Final Maturation of the Hawaiian Limpet Cellana sandwicensis. J Aquac Res Development 5: 256. doi:10.4172/2155-9546.1000256

consistent with synchronized spawning of male and female in the wild.

The GSI of the individual sexes during study period was more carefully examined. Statistical analysis showed that there was a significant $(P<0.0001)$ difference in GSI of males among the monthly measurements from November 2011 to December 2012 (Table 3). The highest GSI of males was $35.3 \%$ for December 2012. This did not differ significantly compared to November 2012 (33.1\%) and November 2011 (30.3\%), but differed significantly compare to other measurements. This suggests that the minimum average mature GSI for males should be about $30.3 \%$. The highest average GSI of females was $30.9 \%$ in November 2012, but there was no significant difference with that GSI of animals in Dec 2012 (24.2\%) and January 2012 (26.5\%). This suggests that the minimum average mature GSI for females should be about $24.2 \%$.

Figure 3 is a set of histology slides of gonad sections of opihi through the resting, final maturation, spawning, and reabsorption phases. The Figure $3 \mathrm{~A}$ showed unclear oocyte formation and eggs being undistinguishable from ovary-cell wall in the ovary of a female that was collected in May 2012, before the final maturation season. These characteristics are considered as resting stages which were frequently observed from February to August. In the following Figure 3B, multiple development stages were seen in the same ovary of a female that was collected in October (during the final maturation season and before

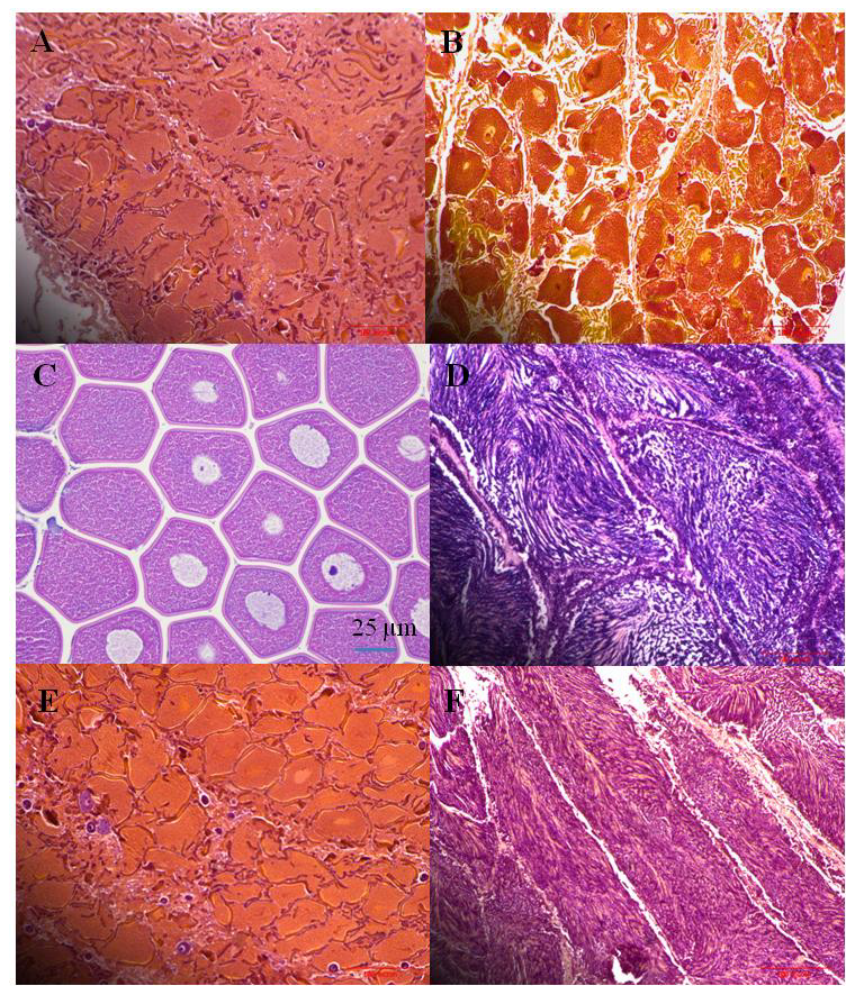

Figure 3: Cross-sections showing stages of opihi C. sandwicensis gonad development.

A.Resting development stages of female (May 2012).

B. Early development stages in ovary of female (October 2012).

C. mature female gonad and some oocytes were still in late development stage (November 2012).

D. mature male gonad with dark blue stained by hematoxylin (November 2012)

E. post-spawning or reabsorption with oocytes deforming shape in the ovary (February 2012) and

F. immature gonad of male (February 2012).

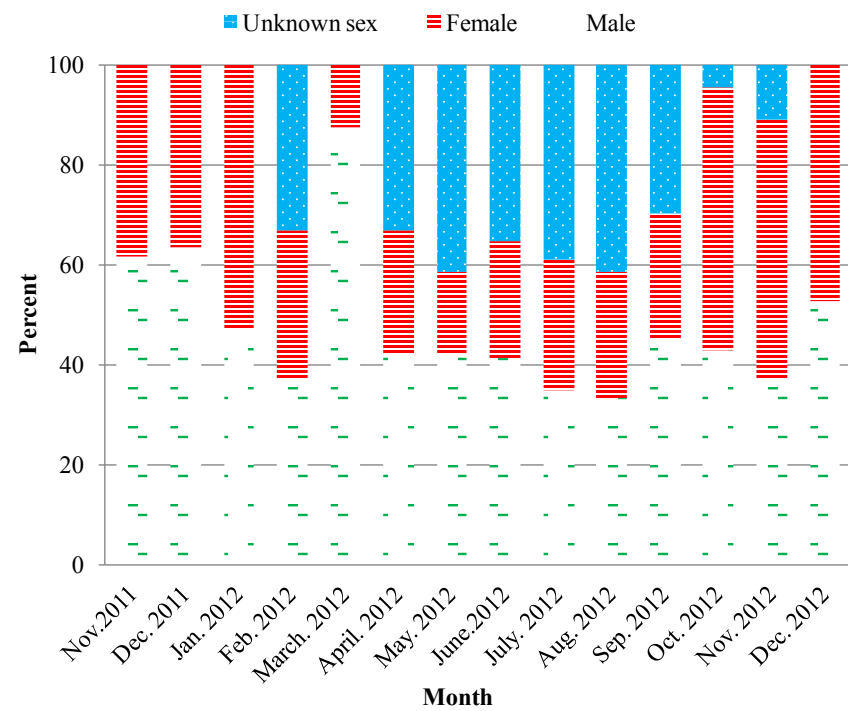

Figure 4: Monthly distribution of sexes of Cellana sandwicensis from November 2011 to December 2012

GSI peak). Multiple development stages were seen in ovary of a female collected in this month. Most of the oocytes were in the early stages and few in the late development stages. This indicates that the animals were immature during this period. Maximum ripeness for both sexes was observed in November (11/25/12) and the cross-section of mature ovary and testis are shown in the Figures $3 \mathrm{C}$ and $3 \mathrm{D}$. About $80 \%$ of oocytes were ripe in ovary with GSI of $24.8 \%$. Most of the oocytes appeared mature, large with similar sizes $(>100 \mu \mathrm{m})$, and showed a round shape. Egg membranes were distinct and separated the eggs from the rest of the ovary. Similar observation was made for gonad of the male (Figure 3D). The testes were densely packed with spermatozoa which appeared dark blue stained by hematoxylin. In the post spawning and reabsorption phase, several development stages were seen in the same ovary of a female that was collected in February (02/28/12) (Figure 3E). Most of the oocytes were deformed in shape, consistent with reabsorption, and several oocyte stages were present. Sperm were less dense in the male gonad (Figure 3F). Spermatozoa tested did not stain dark blue and were mostly pink in color.

Figure 4 shows the distribution of sexes of opihi collected monthly during the reproductive cycle study. Among a total of 266 wild caught opihi, there were 126 males, 92 females and 48 whose sex was unknown. The sex ratio was approximately 1.4:1 for male: female. However, the ratio appeared to be 1:1 during spawning season (November to January) and in all of the animals sexed after dissection. As indicated previously sexing and ripeness evaluation was not done on live animals because the gonad of opihi is covered by the muscular foot. Failures in sexing the animals occurred from April to September due to immaturity of the gonad, which was also associated with the lowest GSI.

Figure 5 shows the estimated total number of oocytes in ovaries of mature opihi during the spawning season. Fecundity (F) or total eggs counted of mature female opihi ranged from $39 \times 10^{3}$ to $124 \times 10^{3}$ eggs per g body weight of females greater than $40 \mathrm{~mm}$ in shell length. Fecundity was linearly correlated to body weight $(P=0.019)$ rather than shell length. The respective relationship is best described by the equations: $\mathrm{F}=28.1 \mathrm{BW}-74.6\left(\mathrm{R}^{2}=0.98\right)$. The number of eggs was generally proportioned to body weight (soft body tissue) rather than shell length. 
Citation: Hua NT, Ako H (2014) Reproductive Biology and Effect of Arachidonic Acid Level in Broodstock Diet on Final Maturation of the Hawaiian Limpet Cellana sandwicensis. J Aquac Res Development 5: 256. doi:10.4172/2155-9546.1000256

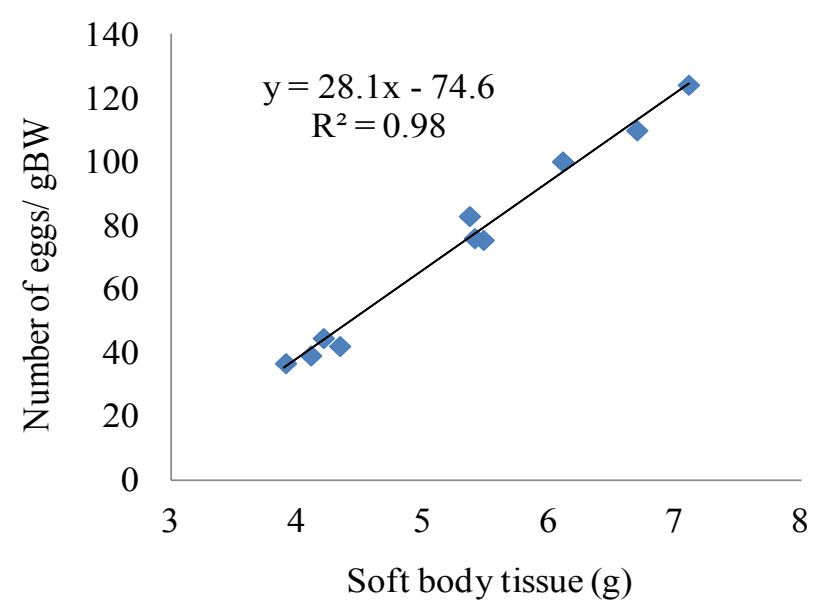

Figure 5: Number of eggs versus soft body weight of mature opihi Cellana sandwicensis $(n=10)$ during the spawning season. The regression line of best fit the relationship between the two factors and $R$ values indicates the strength of the relationship.

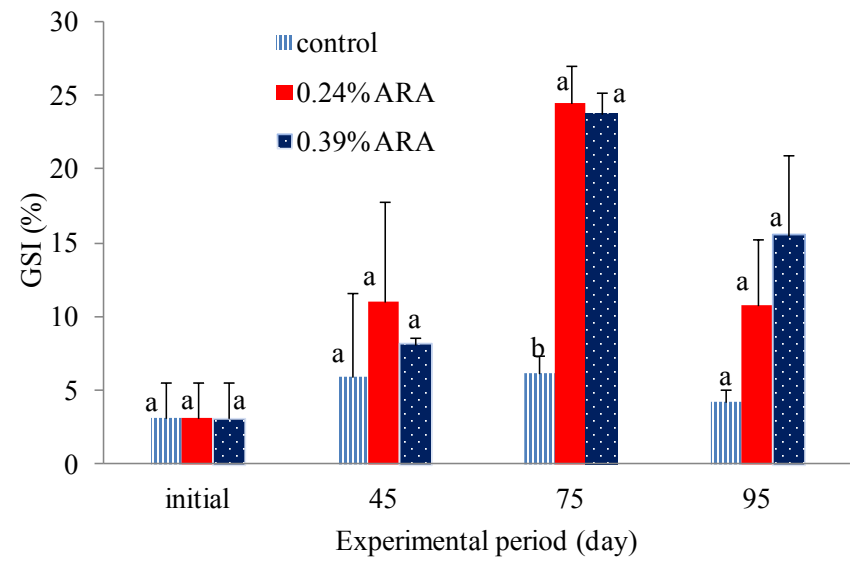

Figure 6: Gonadal somatic index of opihi $C$. sandwicensis fed various ARA diets. $a, b$ different letters indicate significantly difference in mean GSI $(n=3)$ of opihi within the same date of sampling.

\section{Induction of final maturation}

Gonad development of broodstock fed with different ARA diets are shown in the Figure 6. There was a technical error due to not correcting the impurity of ARA before adding to the feed which led to a lower ARA level in both diets than the needed levels of $0.24 \%$ ARA and $0.39 \%$ ARA. These incorrect ARA diets were fed to animals for the first 45 days (Sep. 23 $3^{\text {th }}$ 2013-Nov. 05 ${ }^{\text {th }}$ 2013). The incorrect ARA/ EPA of $0.24 \%$ ARA diet was 0.12 which is lower than the desired ARA/ EPA ratio of 0.70 . The GSI values of the animals were $11.0 \%$ for $0.24 \%$ ARA and $8.10 \%$ for $0.39 \%$ ARA, but there was no significant $(P>0.05)$ difference compared to the GSI (5.94) of animals that were fed with the control diet without additiona of ARA for over the 45 days period. The mistake was then corrected and the GSI of the animals reached the final maturity stage when they were fed with both additional ARA diets up to day 75 (November $6^{\text {th }}$ 2013-December $05^{\text {th }}$ 2013). The GSI of the animals fed with both ARA diets increased three times more than the GSI of animals that were fed with the control diet and about two times more than the GSI of the animals in the first 45 days. The mature eggs of animals fed with $0.24 \%$ ARA and $0.39 \%$ ARA diets was $123 \pm$ $4.23 \mu \mathrm{m}$ and $121 \pm 5.93 \mu \mathrm{m}$ respectively. There was no significant $(P$ $>0.05)$ difference in the size of egg between the two ARA diets. No female was sampled at this measurement for control at this time. The GSI of animals decreased in all diets after 95 days (Dec. $6^{\text {th }}$ 2013-Jan. $06^{\text {th }} 2014$ ). At this point in time the animals could have undergone reabsorption because the ovaries were deformed and was difficult to measure the ovaries' size exactly under the compound microscope. The gonads of animal in the control were immature.

A histological study confirmed the gonad development of animals when they were fed with ARA diets (Figure 7). The initial female's gonad contained slack oocytes, which did not have defined shapes (panel A, Figure 7A). The cross-section of ovaries of animals that were fed with the incorrect $0.24 \%$ ARA and $0.39 \%$ ARA showed that the oocytes were clearly formed but contained multiple stages and various sizes in the first 45 days (Figures $7 \mathrm{~B}$ and $7 \mathrm{C}$ ). These indicate that the gonads of animals had not yet developed to the mature stage at this time. Stage 2 is an early maturity stage with small oocyte diameter (7.0$10 \mu \mathrm{m})$. In stage 3, oocyte cells have a large central lumen and were most frequently seen (about 48-55\%). A few oocytes (6-10\%) have already turned into mature stages. After being fed with the correct diet, the ovary cells grew in both diets up to 75 days period. Figures $7 \mathrm{D}$ and 7E showed that most of the eggs were in stage 4 (about 73\%), which was defined as a ripe stage, and the egg's membrane were separated and round shaped. Eggs were deformed in shape after 95 days (Figure $7 \mathrm{~F}$ ).

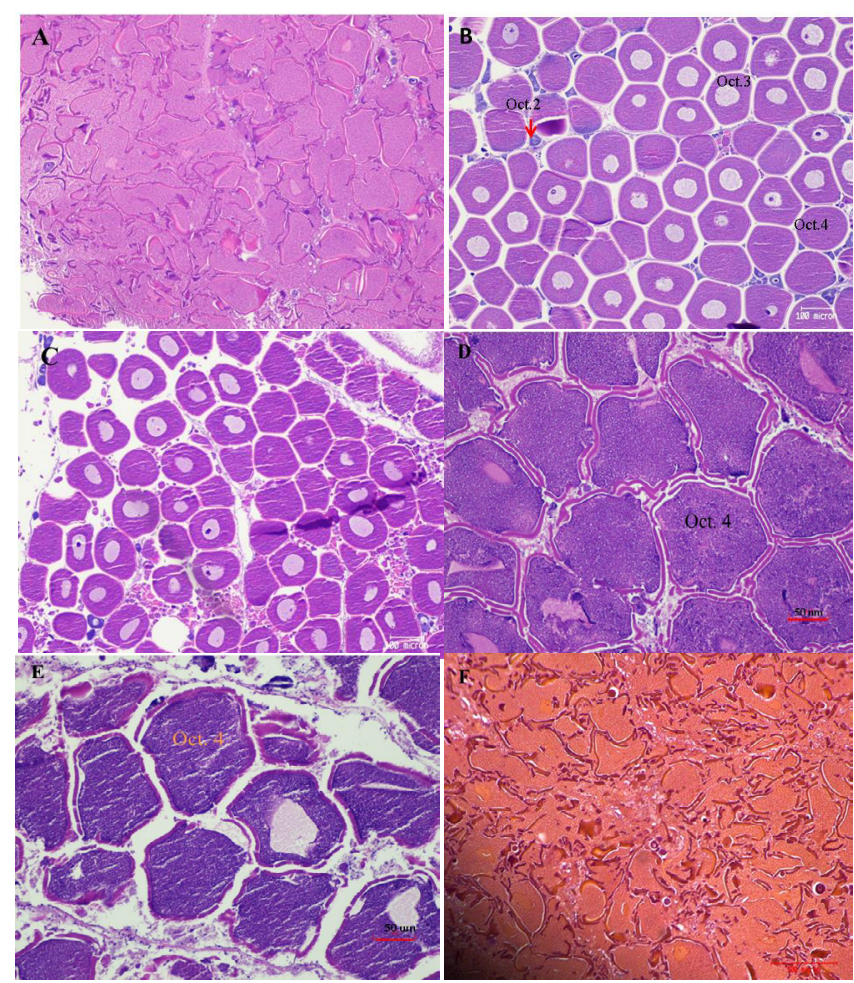

Figure 7: Cross-section ovary of opihi C. sandwicensis stained with hematoxylin-eosin.

A.Initial immature female's gonad.

B. The gonad of female that fed with incorrect $0.24 \%$ ARA diet for 45 days

C. The gonad of the female that fed high incorrect $0.39 \%$ ARA diet for 45 days

D.Ovary at 75 days fed with correct $0.24 \%$ ARA diet ( $x 40)$.

E.Ovary at 75 days fed with correct $0.39 \%$ ARA diet (x40) and

F.Female gonad at 95 days fed with $0.39 \%$ ARA diet. 


\section{Discussion}

In the present study, the spawning season of opihi C. sandwicensis was examined based on the examination of GSI with histological analysis of collected animals monthly. The GSI and histology studies suggest the winter spawning season for opihi C. sandwicensis. The GSI for November, December and January were high and significantly higher than those of GSI in other months from February to September (non-spawning season). Similarly, the GSI for males and females separately were also much higher than GSI of other months sampled. Histology photos for the gonad of females and males sampled in November (Figure 3C and 3D) confirmed that they were ripe. The GSI data for December 2011 was an outlier or could mean that the group of animals sampled had just spawned before the sampling. The GSI data for December 2012 was consistent with the spawning season and higher than others during non spawning season. The male GSI was also significantly higher than the GSI during the non-spawning season and the GSI for females was higher but overlapping with others during non spawning season. This overlap was contradicted by the histology photo for December 2012 of the mature female which was the same as November 2012. Oocytes were round, had distinguishable cellmembranes. Spermatozoa were condensed in the male's gonad.

The GSI value for January 2012 was also significantly higher than the GSI during non-spawning season. Similarly, the GSI for males and females was higher than in non spawning seasons although there was some overlap for males. The histology for females showed mature ovaries, but for males testes were questionably mature. The data suggest that a portion of male opihi population might have been spent or that the males began spawning prior to females in January. Similar patterns have been observed for other limpet species $P$. vulgate and P. ulyssipoensis $[7,20]$. Thus, the spawning season of $C$. sandwicensis commenced in November and would extend to January.

The non-reproductive season for yellow foot opihi was proposed to occur from the mid-spring to the summer time. The winding down phase occurred in February, after the spawning period. The GSI data for February $2012(9.05 \pm 3.65 \%)$ was winding down and it was significantly lower than ripe samples during the spawning season, and it did not differ significantly compared to GSIs that collected from February to September 2012. Histology photos for February of female and male are shown in Figure $3 \mathrm{E}$ and $3 \mathrm{~F}$. The GSIs in the following months up to September 2012 were low and remained at the same level. Histology observations for female's gonad in these months were the same as May 2012 (Figure 3A), the oocyte-cell membrane was not clear, and there were a few stage I oocytes. This was true for spermatids as well. The testis was less viscous and it did not stain darkly. This was most frequently seen during March to September of the year. This period could also be called the non-spawning season or reproductive resting phase.

This is followed by a development stage begin in October. GSI for October $(18.7 \pm 7.77 \%)$ was significantly higher than the GSI during non-reproductive season. GSI for separated males $(23.8 \pm 7.78 \%)$ was significant higher than most the GSI levels during the non spawning season, but GSI for females $(16.1 \pm 6.86 \%)$ did not differ significantly with non spawners during the non spawning season. The GSI for females may not be indicative of ripeness. It seemed that the gross weight of ovaries was not very changeable in microanatomy as seen by histology. A histology photo for October is shown in the Figure 3B. Several oocytes were in the late development stages. No histology analysis was examined for males in October. These data indicate that the gonad of both males and females were progressing in development, in preparation for a new spawning season.

In conclusion, the results of this study indicate that the natural spawning season of the yellow food opihi C. sandwicensis occurs from November to December and could be extended to January. However, the number of spawnings during the season was not known and our data might be tainted by spawning within the season. Laboratory spawning observations need to be done in the future. The non-spawning season or resting phase for yellow foot opihi appears to occur from late February to early September and gametogenesis development processes is proposed to occur in late September to October in preparation for another spawning cycle.

The overall sex ratio over the month sampled showed that the male yellow opihi was more abundant than the female with an approximate ratio of 1.4:1. Our finding was similar to other studies for limpets. For example, a sex ratio of 1.4 male to 1 female limpet $P$. vulgata was found [7]. A similar finding was that the male limpet $P$. depressa as more dominant than the female [21]. However, our present study found that sex ratio was even for male and female during the spawning season which was different with other studies for limpets. The sex of a large number of opihi could not be determined during non-spawning or post spawning season due to the low GSI during this period, which may have produced the apparent sex differential.

As stated previously, collecting opihi is prohibited by law which regulates the harvest size for all Cellana to those over 1.25 inches (approximately $3.2 \mathrm{~cm}$ ). We avoided collecting animals that were smaller than the regulated size. All experimental animals in this study complied with current law in Hawaii. Therefore, we were not able to determine the smallest size at which the yellow opihi attain sexual maturity. Other studies reported that $C$. sandwicensis could reach the reproductive stage at a shell length of $2.3 \mathrm{~cm}$ to $2.5 \mathrm{~cm}$ or larger [5]. Opihi C. exarata could attain sexual maturity at a smaller size of about $1.8 \mathrm{~cm}$ shell length under laboratory conditions [18]. This could be due to sufficient provision of benthic diatoms for the opihi in the laboratory.

Food availability and the quality of feed for animals are considered to be critical factors that induce final maturation and spawning in invertebrate species [22]. There is a relationship between food supply and gametogenesis for scallop Pecten maximus [22]. Increasing food availability (diatoms and phytoplankton) during spring season was correlated to the spawning season of limpet Nacella concinna [23], suggesting that the immature animal needs food to grow and to develop its gonad. This work confirms and adds to that observation. The diatom Navicula blooms at a time suggesting that it may be a trigger for seasonal ripening of mullet broodstock [11]. It is rich in arachidonic acid and this may indicate enrichment of the essential nutrient arachidonic acid in diatoms, triggering seasonal maturation. It is believe that ARA plays an important role in the reproductive process of many marine fishes [12,10]. However, most of these marine animals have limited eicosanoid enzymes that convert omega- 6 and omega-3. For example, abalone have a limited ability to convert $18: 2 n-6$ to $20: 4 n-$ 6 and 18:3n-3 to 20:5n-3, and the process of bioconversion might occur at a low rate [24]. A low bioconversion rate would lead to a low level of 20:4n-6 and would result low levels of prostaglandins. Therefore, there is a requirement of animals for $20: 4 n-6$ in their maturation diet if the animals are unable to elongate and desaturate it sufficiently from $18: 2 \mathrm{n}-6$.

In the present study, the inclusion of $0.24 \%$ and $0.39 \%$ ARA in the diet produced final maturation in opihi after 75 days. The gonad of 
Citation: Hua NT, Ako H (2014) Reproductive Biology and Effect of Arachidonic Acid Level in Broodstock Diet on Final Maturation of the Hawaiian Limpet Cellana sandwicensis. J Aquac Res Development 5: 256. doi:10.4172/2155-9546.1000256

Page 7 of 8

animals reached the final maturity level of $24.5 \%$ GSI for $0.24 \%$ ARA diet and $23.7 \%$ GSI for $0.39 \%$ ARA. These values were found to be the lowest mature level for female GSI in the above study. The egg sizes were $123 \pm 4.23 \mu \mathrm{m}(0.24 \%$ ARA diet $)$ and $121 \pm 5.93 \mu \mathrm{m}(0.39 \%$ ARA diet) which indicated that they were mature. Consistently, histology photos for females fed with these diets demonstrated most of the oocytes in mature stages (Figures 7D and 7E). This indicates that an ARA/EPA ratio of 0.70 performed well to enhance the reproductive process of opihi. A similar ratio of ARA/EPA was also found to be effective for inducing final maturation in fish $[11,12]$ or a lower ratio of 0.5 for shrimp [13]. There was no significant difference in gonad maturation of opihi that were fed with $0.24 \%$ and $0.39 \%$ ARA levels indicating that the different ARA levels did not affect the maturation process. This suggests that the dietary ratio of ARA/EPA may play an important nutritional role in promoting the final maturation of opihi. It may be an optimal ratio for prostaglandin synthesis. It is known that there is competition between EPA and ARA for the enzyme systems producing eicosanoids [25] which could be the reason the ratio is important.

A moderate increase in GSI of the animals in the first 45 days (Sep. $23^{\text {th }}$-Nov. $05^{\text {th }} .2012$ ) could be due to the incorrect addition of ARA to the diets. The gonad of animals fed with these incorrect ARA diets were improved only slightly (8.13-11.0\%) compared to the control group (5.94\%). Presumably, the animals would have reached final maturation earlier if the error did not happen. The improvement of GSI of animals even they were fed with incorrect ARA diets for 45 days, suggests that the photoperiod might facilitate the gametogenesis process of opihi. Photoperiod has also been reported to be influential on reproductive cycles of many marine invertebrates [26-28]. Experiments in the laboratory showed that when sea urchin Eucidaris tribuloides were held under longer daylenght (15L: 9D), gametogenesis was delayed over the entire year [28]. The animals that were held under short days (9:15; light: dark) produced mature gonad throughout the year. Another study found that the reproductive resting phase of C. exarata coincided with day length above $13 \mathrm{hr}$ from May to August (in Hawaii), suggesting that a higher $13 \mathrm{hr}$ day length could inhibit gametogenesis of opihi [18]. In fact our preliminary maturation trial (data not shown) also found that that the opihi did not reach the final maturation when they were fed a diet without supplementation of ARA during this period (May-August). These results reveal that the presence of ARA, even at low levels, in collaboration with a favorable environment would also enhance the proliferation process of opihi.

The GSI was winding down after 95 days for both $0.24 \%$ ARA $(10.8 \pm 4.47 \%)$ and $0.39 \%$ ARA $(15.5 \pm 5.47 \%)$ diets as compared to the GSI of a day 75 measurement. Cross-sections of the ovary confirmed that most of the mature oocytes had disappeared and the appearance of several stages of oocytes in the ovary indicates the animals may have undergone natural reabsorption. The mature animals did not undergo final spawning. This may be due to the wrong photoperiods, after spawning season the diet may not be effective. In the other hand, it could be due to the lack of an external environmental factor that would be responsible for triggering spawning at the window end point. Successful spawning in most mollusk species requires a combination of both endogenous and exogenous factors [4]. Several exogenous factors are considered to induce spawning in limpets such as temperature, wave action or vigorous water movement and storms $[4,29,30]$. This suggests that an induction of spawning by using an appropriate method should have been used to spawn the mature opihi soon after the 75 days. Nevertheless, this study concluded that an appropriate ARA/EPA ratio of 0.70 in the maturation diet would induce final maturation of opihi and will be useful for future practical reproduction in hatchery conditions. We believe that this is the first study of the effect of ARA/ EPA on maturation of Hawaiian limpets and gastropod species as well.

\section{Acknowledgement}

This study was supported financially by the Center for Tropical and Subtropical Aquaculture, USA, grant \#@2009-210 and the Vietnam Educational Foundation. The authors thank Dr. Ju (Oceanic Institute) for fatty acid analysis.

\section{References}

1. lacchei M (2011) Managing fisheries for future. Ka Pili Kai 33: 3-5

2. Bird CE (2011) Morphological and behavioral evidence for adaptive diversification of sympatric Hawaiian limpets (Cellana spp.). Integrative and Comparative Biology 51: 466-473.

3. Hua TN, Ako H (2012) Enabling studies for aquaculture of the Hawaiian Opihi, the Limpet Cellana. World Aquaculture Society 12: 40-44.

4. Hahn K (1989) CRC Handbook of culture of abalone and other marine gastropods. CRC Press, Florida, USA.

5. Kay EA, Magruder W (1977) The biology of opihi. Department of planning and economic development, Honolulu, USA.

6. Fletcher WC (1988) Reproductive effort in two subtidal populations of the limpet, Patelloida murfria. Oecologia 74: 586-591.

7. McCarthy M, Woosnam P, Culloty SC (2008) Histological investigation of the reproductive cycles of limpets Patella vulgate and Patella ulyssiponensis. Marine Biology 153: 871-877.

8. Watanabe T, Itoh A, Murakami A, Tukashima Y, Kitajima C, et al., (1984) Effects of nutritional quality of diets given to broodstock on the verge of spawning on reproduction of red sea bream. Bulletin of the Japanese Society Fishery 50: 1023-1028.

9. Stacey NE, Goetz FW (1982) Role of prostaglandins in fish reproduction. Can $J$ Fish Aqua Sci 39: 92-98

10. Schimz G, Ecker J (2008) The opposing effect of n-3 and n-6 fatty acids. Progress in Lipid Research 47: 147-155.

11. Tamaru CS, Ako H, Lee CS (1992) Fatty acid and amino acid profiles of spawned eggs of striped mullet, Mugil cephalus L. Aquaculture 105: 83-94.

12. Furuita H, Yamamoto T, Shima T, Suzuki N, Takeuchi T (2003) Effect of archidonic acid levels in broodstock diet on larval and egg quality of Japanese flounder Paralichthys olivaceus. Aquaculture 22: 725-735.

13. Coman GJ, Arnold SJ, Barclay M, Smith DM (2011) Effect of arachidonic acid supplementation on reproductive performance of tank-domesticated Penaeus monodon. Aquaculture nutrition 17: 141-151.

14. Bautista-Teruel MN, Millamena OM, Fermin AC (2001) Reproductive performance of hatchery-bred donkey's ear abalone, Haliotis asinina, Line, fed natural and artificial diets. Aquaculture research 32: 249-254.

15. Volkman JK, Jeffrey SW, Nichols PD, Rogers GI, Garland CD (1989) Fatty acid and lipid composition of 10 species of microalgae used in mariculture. Journal of Experimental Marine Biology and Ecology 128: 219-240.

16. Ako $H$ (1995) Algae in the Aquaculture of Marine Fishes and Shrimps Sustainable Aquaculture 95.

17. Gordon N, Neori A, Muki S, Lee J, Harpaz S (2006) Effect of diatom diets on growth and survival of the abalone Haliotis discus hannai postlarvae. Aquaculture 252: 225-233.

18. Corpuz GC (1983) Life history traits influencing vertical zonation in the Hawaiian intertidal species of Cellana. University of Hawaii, Manoa, Hawaii, USA.

19. Ju ZY, Forster IP, DominyWG (2009) Effects of supplementing two species of marine algae or their fractions to a formulated diet on growth, survival and composition of shrimp (Litopenaeus vannamei). Aquaculture 292: 237-243.

20. Bowman RS (1985) The morphology of Patella spp juveniles in Britain and some phylogenetic inferences. Journal of the Marine Biological Association of the United Kingdom 61: 647-666.

21. Morias S, Boaventura D, Narciso L, Re P, Hawkins SJ (2003) Gonad development and fatty acid composition of Patella depressa Pennat (Gastropoda: Prosobranchia) populations with different patterns of spatial 
Citation: Hua NT, Ako H (2014) Reproductive Biology and Effect of Arachidonic Acid Level in Broodstock Diet on Final Maturation of the Hawaiian Limpet Cellana sandwicensis. J Aquac Res Development 5: 256. doi:10.4172/2155-9546.1000256

Page 8 of 8

distribution, in exposed and sheltered sites. Journal of Experimental Marine Biology and Ecology 294: 61-80.

22. Soudant P, Marty Y, Moal J, Quere C, Le Coz JR, et al., (1996) Effect of food fatty acid and sterol quality on Pecten maximus female gonad composition and reproduction process. Aquaculture 143: 361- 378.

23. Bresthes JC, Ferreyra G, De La Vega S (1994) Distribution, growth and reproduction of limpet nacelle (Patinigera) concinna (Strebel 1990) in relation to potential food availability, in Esperanza Bay (Antarctic Penisula). Polar Biology 14: $161-170$

24. Uki N, Sugiura M, Watanabe $T$ (1986) Requirements of essential fatty acids in the abalone Haliotis discus hannai. Nippon Suisan Gakkaishi 52: 1013-1023.

25. Sargent JR, Bell JG, McEvoy L, Tocher DR, Estevez A (1999) Recent developments in the essential fatty acid nutrition of fish. Aquaculture 177: 191199.
26. Giese AC (1959) Comparative physiology: animal reproductive cycles of marine invertebrates. Annual Review of Physiology 21: 547-576.

27. Giese AC, Pearse JS (1979) Reproduction of marine invertebrates. Academic Press, New York, USA.

28. McClintock J, Watts S (1990) The effects of photoperiod on gametogenesis in the tropical sea urchin Eucidaris tribuloides. Journal of Experimental Marine Biology and Ecology 139: 175-184.

29. Delaney J, McGrath D, O'Riordan R, Meyers AA (2002) Reproduction in the intertidal limpets Patella vulgate and Patella ulyssiponensis. Marine intertidal ecology. Royal Irish Academy, Dublin, Ireland.

30. National Research Council (1981) Nutrient Requirements of Coldwater Fishes National Academy Press, Washington D.C, USA. 